\title{
Enteral Tryptophan Requirement Determined by Oxidation of Gastrically or Intravenously Infused Phenylalanine Is Not Different from the Parenteral Requirement in Neonatal Piglets
}

\author{
SUZAN CVITKOVIC, ROBERT F.P. BERTOLO, JANET A. BRUNTON, PAUL B. PENCHARZ, AND \\ RONALD O. BALL \\ Department of Agricultural, Food and Nutritional Science, University of Alberta, Edmonton, Alberta, \\ Canada T6G 2P5 [S.C., P.B.P., R.O.B.], Department of Biochemistry, Memorial University of \\ Newfoundland, St. John's, Newfoundland, Canada A1B $3 X 9$ [R.F.P.B., J.A.B.], The Research Institute, \\ Hospital for Sick Children, Toronto, Ontario, Canada M5G 1 X8 [P.B.P., R.O.B.], and Department of \\ Paediatrics [P.B.P.] and Department of Nutritional Sciences [P.B.P., R.O.B.], University of Toronto,
} Toronto, Ontario, Canada M5S 1 A1

\begin{tabular}{|c|c|}
\hline \multicolumn{2}{|c|}{ ABSTRACT } \\
\hline 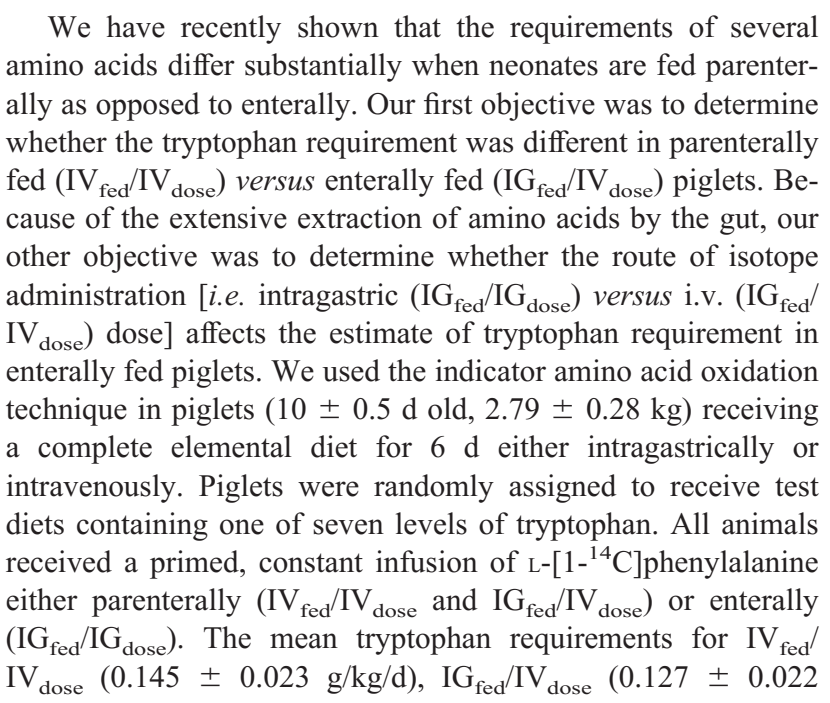 & $\begin{array}{l}\mathrm{g} / \mathrm{kg} / \mathrm{d}) \text {, and } \mathrm{IG}_{\text {fed }} / \mathrm{IG}_{\text {dose }}(0.113 \pm 0.024 \mathrm{~g} / \mathrm{kg} / \mathrm{d}) \text { were similar as } \\
\text { were the safe intakes (upper } 95 \% \text { confidence interval) }(0.185 \text {, } \\
0.164,0.154 \mathrm{~g} / \mathrm{kg} / \mathrm{d} \text {, respectively). These data indicate that tryp- } \\
\text { tophan is not extensively used by the gut, in contrast to all the } \\
\text { other amino acids we have studied. Furthermore, in spite of a } \\
\text { splanchnic extraction of } 27 \% \text { of the phenylalanine dose, the route } \\
\text { of isotope infusion does not affect the tryptophan requirement as } \\
\text { determined by indicator amino acid oxidation. (Pediatr Res 55: } \\
\text { 630-636, 2004) Abbreviations } \\
\text { CI, confidence interval } \\
\text { IAAO, indicator amino acid oxidation } \\
\text { IG, intragastric } \\
\text { IV, intravenous } \\
\text { SEE, SE of the estimate } \\
\text { SRA, specific radioactivity } \\
\text { TPN, total parenteral nutrition }\end{array}$ \\
\hline
\end{tabular}

Due to physiologic immaturity and disease, premature infants often require TPN (1). The amino acid solutions currently used in TPN are mostly based on oral reference proteins, such as whole egg protein and human milk protein (2). Because nutrients infused parenterally bypass both liver and gut firstpass metabolism, the use of these amino acid solutions may be inappropriate for parenterally fed infants (2). For example,

Received January 16, 2003; accepted October 23, 2003.

Correspondence: Ronald O. Ball, M.D., 4-10 Agriculture/Forestry Centre, University of Alberta, Edmonton, AB, Canada T6G 2P5; e-mail: rball@afns.ualberta.ca

Supported by the Natural Sciences and Engineering Research Council of Canada, the Alberta Agricultural Research Institute, and Canadian Institutes of Health Research Fund Grant \#MOP-12928.

DOI: 10.1203/01.PDR.0000113788.85515.7E
Bertolo et al. (3) showed that the parenteral threonine requirement of neonatal piglets was approximately $45 \%$ of the mean enteral requirement. In parenteral feeding, nutrients infused into a central vein bypass exclusive first-pass metabolism by the intestine and liver; these nutrients are therefore provided to nonsplanchnic organs in concentrations that are not modified by first-pass splanchnic metabolism. In piglets fed complete diets via a central or portal vein, we have previously shown that both routes of feeding led to extensive gut atrophy, and hence lowered intestinal metabolic capacity (4). These studies also demonstrated that in parenterally fed piglets, gut atrophy has a greater impact on nitrogen metabolism than bypass of first-pass liver metabolism $(4,5)$. In support of this conclusion, 
other investigators have also shown that approximately one third of the dietary indispensable amino acids is consumed by the healthy intestine on first pass alone (6). Therefore, the parenteral requirements of amino acids need to be determined separately to accommodate the extensive splanchnic metabolism that is bypassed during parenteral nutrition feeding.

We have recently developed the IAAO technique for determining indispensable amino acid requirements in parenterally fed piglets (7). Because the neonatal piglet is an appropriate model for the premature infant (8), we have used the piglet to study amino acid requirements during parenteral feeding due to its low interindividual variance, availability, and lack of complicating illnesses that necessitated TPN in the first place. Classically, in the IAAO, the isotopically labeled indicator amino acid is infused intravenously and serial blood samples are collected to measure amino acid enrichments. Recently, we have developed a minimally invasive adaptation of the technique for infants by infusing isotopes orally and collecting urine to measure enrichments (9). These adaptations allow us to use the IAAO technique in several vulnerable populations such as infants, children, women, and unhealthy individuals.

However, several researchers have recently demonstrated that $20-60 \%$ of enterally delivered indispensable amino acid tracer is extracted by the splanchnic tissues, which affects the quantity of isotope reaching the central plasma pool and alters flux rate measurements $(10-17)$. In particular, $19-58 \%$ of enteral phenylalanine tracer is extracted on first pass (10-12). Therefore, because amino acid kinetic measurements are affected by route of isotope infusion, requirement estimates determined using oral versus IV infusion may be different. Although several investigators have studied the effect of the route of tracer administration on amino acid kinetics (11-17), only our group (10) has examined the effect of the route of isotope administration on amino acid requirement estimates. In that study, we determined that route of isotope infusion had no effect on oral lysine requirements in healthy human adults.

In the current study, our first objective was to study the impact of route of feeding (i.e. TPN feeding) on the requirement of tryptophan in the neonatal piglet using the IAAO technique. Unlike threonine, which is involved in the production of gut mucins, tryptophan has not been implicated to play a major role in gut function apart from protein synthesis. We hypothesized that unlike threonine, which is disproportionately used by the gut $(3,6)$, the tryptophan requirement in parenterally fed piglets would be similar to or slightly lower than that in enterally fed piglets, proportionate to the decrease in protein synthesis associated with gut atrophy during parenteral feeding $(7,18)$. Our second objective was to determine whether the enteral tryptophan requirement estimate differs if phenylalanine isotope is delivered intragastrically instead of intravenously. We hypothesized that splanchnic extraction of phenylalanine will affect kinetic parameters, but will not affect the overall break point pattern or estimate of requirement.

\section{METHODS}

Animals and surgical procedures. All procedures were conducted in accordance with the Canadian Council of Animal Care and approved by the local animal care committee. Yorkshire piglets were all sow fed for $1-2 \mathrm{~d}$ and weighed $1.62 \pm 0.16 \mathrm{~kg}$ at entry. A schematic outline of the treatment protocol is shown in Figure 1. In experiment 1 (parenteral feeding, i.v. dose or $\mathrm{IV}_{\text {fed }} /$ $\left.\mathrm{IV}_{\text {dose }}\right), 16$ piglets ( 8 male, 8 female) were obtained from the University of Alberta's Swine Unit and surgically fitted with jugular catheters for isotope infusion and femoral catheters for blood sampling. In each of experiments 2 (enteral feeding, IV dose or $\mathrm{IG}_{\text {fed }} / \mathrm{IV}_{\text {dose }}$ ) and 3 (enteral feeding, IG dose or $\mathrm{IG}_{\text {fed }} /$ $\left.\mathrm{IG}_{\text {dose }}\right), 18$ intact male piglets from Shooter's Hill Livestock Inc. (Calmar, AB, Canada) were transported to the University of Alberta and implanted with jugular, femoral, and gastric catheters. It is important to note that both the University of Alberta and Shooter's Hill Livestock receive their genetic stock from the same source. More detailed descriptions of the surgical procedures can be found elsewhere $(3,8)$. After surgery, all piglets were fitted with a jacket containing an anchoring button as part of a tetherswivel system used to secure and protect the implanted catheters. Postsurgical treatment and housing conditions have been described previously (8).

Diet regimen. The elemental diet used was based on that developed by Wykes et al. (8), with some modifications, and was designed to supply all of the nutrients required by piglets. The diet provided 1.1 MJ available energy per $\mathrm{kg}$ of body weight daily and 15.6, 27.4, and $9.4 \mathrm{~g}$ of amino acids, glucose, and fat per kilogram of body weight per day, respectively. Glucose and lipids each supplied $50 \%$ of the nonprotein energy intake. The base amino acid profile of the diet was (milligram per gram of total L-amino acids): alanine, 103; arginine, 77; aspartate, 58; cysteine, 14; glutamate, 102; glycine, 46; histidine, 30; isoleucine, 44; leucine, 101; lysine, 80; methionine, 19; phenylalanine, 31; proline, 80; serine, 54; taurine, 4; threonine, 51; tryptophan, 21; tyrosine, 26; and valine, 51 . The base diet provided the equivalent of $0.41,0.48$, and $0.32 \mathrm{~g} / \mathrm{kg} / \mathrm{d}$ of tyrosine, phenylalanine, and tryptophan, respectively, with tyrosine supplied as the soluble dipeptide glycyl-L-tyrosine. This diet was infused continuously by peristaltic pump to all animals, either enterally or parenterally, immediately after surgery until approximately $2100 \mathrm{~h}$ on d 5. At this time, animals were randomly assigned to receive one of seven test diets containing one of the following levels of tryptophan: $0.025,0.05,0.10,0.15,0.20,0.30$, or $0.40 \mathrm{~g} / \mathrm{kg} / \mathrm{d}$. L-Alanine was used to make all diets isonitrogenous. After the oxidation measurements on the morning of $\mathrm{d} 6$, piglets were returned to their cages and infusion of the base diet was resumed. At approximately $2100 \mathrm{~h}$ on $\mathrm{d} 7$, piglets were again randomly assigned to one of the other six test diets. A second oxidation period was completed on $\mathrm{d} 8$. We have previously demonstrated (unpublished experiments) that this double oxidation protocol has no time or carryover effect on oxidation measurements. In the current study, the test levels fed on $\mathrm{d} 6$ and 8 were randomized and no effect of oxidation day was detected.

Oxidation measurements. Tracer infusion and sample collection during oxidation periods were based on the methods of House et al. (18), with some minor modifications. On d 6 and 8, animals were transferred to covered Plexiglas boxes for the oxidation studies. Air was drawn through the boxes by pump at $20-23 \mathrm{~L} / \mathrm{min}$, and, after a $30 \mathrm{~min}$ equilibration period, pigs 


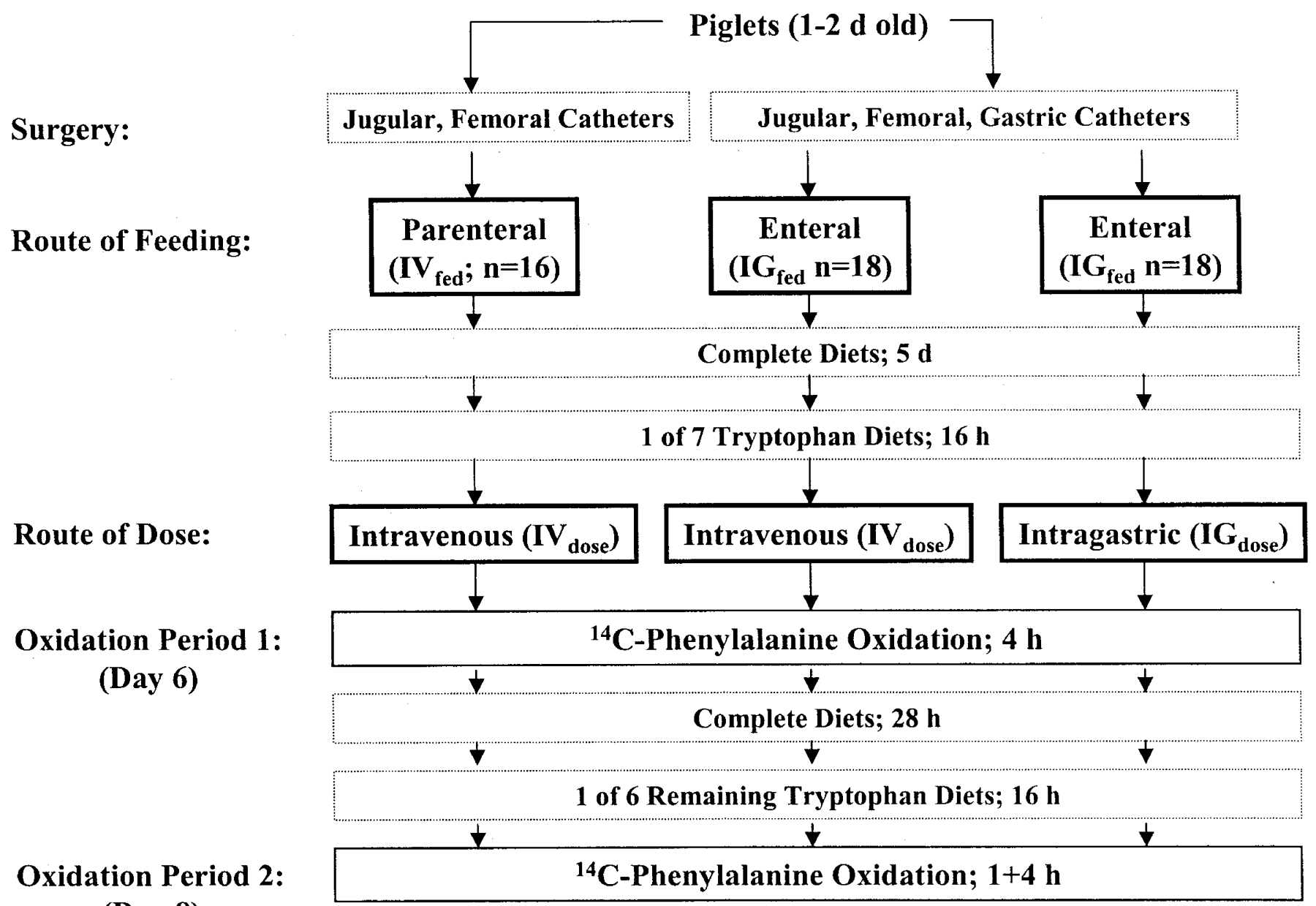

Figure 1. Schematic outline of the treatment protocol for L- $\left[1-{ }^{14} \mathrm{C}\right]$ phenylalanine oxidation studies in parenterally and enterally fed piglets infused with IV or IG isotopes.

were infused with a primed $(185 \mathrm{kBq} / \mathrm{kg})$, constant $(4 \mathrm{~h}, 129.5$ $\mathrm{kBq} / \mathrm{kg} / \mathrm{h}$ ) infusion of a tracer solution containing $92.5 \mathrm{kBq} / \mathrm{mL}$ of $\mathrm{L}-\left[1-{ }^{14} \mathrm{C}\right]$ phenylalanine; $\mathrm{IV}_{\text {fed }} / \mathrm{IV}_{\text {dose }}$ and $\mathrm{IG}_{\text {fed }} / \mathrm{IV}_{\text {dose }}$ pigs were infused intravenously, and $\mathrm{IG}_{\mathrm{fed}} / \mathrm{IG}_{\mathrm{dose}}$ pigs received the infusion via the gastric catheter. Expired ${ }^{14} \mathrm{CO}_{2}$ was completely trapped in half-hour aliquots in a series of gas washing bottles containing $\mathrm{CO}_{2}$ absorber (ethanolamine and 2-methoxyethanol, 1:2, vol/vol, Caledon Laboratories, Mississauga, ON, Canada). Blood samples were taken half hourly throughout the infusion and plasma was stored at $-20^{\circ} \mathrm{C}$ until later analysis for phenylalanine SRA. On d 8, the oxidation procedure was repeated except breath collection and blood samples were also taken at 60 and $30 \mathrm{~min}$ before label infusion to measure background radioactivity from the infusion on $\mathrm{d} 6$.

The rate of ${ }^{14} \mathrm{CO}_{2}$ expiration was determined for each collection period by quantifying the total radioactivity collected in the ${ }^{14} \mathrm{CO}_{2}$ absorber using liquid scintillation counting of a 1-mL aliquot of absorber mixed with $5 \mathrm{~mL}$ of scintillant (Atomlight; Dupont Canada, Mississauga, ON, Canada). The total radioactivity expired was divided by the total radioactivity infused for a given collection period to calculate the fractional oxidation rate (i.e. percentage of dose oxidized). Absolute phenylalanine oxidation rate (i.e. $\mu \mathrm{mol} / \mathrm{kg} / \mathrm{h}$ ) was calculated as described previously (18). The SRA of plasma phenylalanine was measured by reverse-phase HPLC using phenylisothiocyanate derivatives (19); plasma was deproteinized using $0.5 \%$ trifluoroacetic acid in methanol. Breath ${ }^{14} \mathrm{CO}_{2}$ excretion and SRA for plasma phenylalanine for each time point during the infusion study were corrected for background radioactivity if necessary and plotted. For all oxidation calculations, plateau values were the mean of the data at the time points within the plateau; all plateaus included at least four time points. Plateaus were visually determined and then verified by determining that the slope was not different from zero using regression analysis.

Statistical analyses. All experiments had a completely randomized design with the tryptophan level in the diet as the main treatment effect. Requirements were estimated using break point analysis with a two-phase linear regression crossover model and the level of safe intake was determined with 95\% CI (SAS; SAS Institute, Cary, NC, U.S.A.), as described elsewhere (20). The data partitioning selected was based on the model that produced the highest regression coefficients and the lowest residual error. The effects of gender, day of oxidation, initial weight, final weight. and average daily gain on phenylalanine fractional oxidation (expressed as percentage of dose oxidized) were examined using multiple regression (SAS Institute). Differences across tryptophan levels within experiments were assessed using ANOVA and Tukey's multiple 
Table 1. Tryptophan concentrations in plasma $(\mu \mathrm{mol} / \mathrm{L}) *$

\begin{tabular}{|c|c|c|c|c|c|c|c|c|}
\hline & \multicolumn{8}{|c|}{ Tryptophan intake (g/kg/d) } \\
\hline $\mathrm{IV}_{\text {fed }} / \mathrm{IV}_{\text {dose }}$ & $\mathrm{ND} \dagger(3)$ & ND (3) & ND (4) & $4^{\mathrm{c}}(4)$ & $17^{\mathrm{bc}}(4)$ & $28^{\mathrm{ab}}(4)$ & $39^{\mathrm{a}}(4)$ & 3 \\
\hline $\mathrm{IG}_{\text {fed }} / \mathrm{IG}_{\text {dose }}$ & ND (5) & ND (5) & ND (5) & $26^{\mathrm{b}}(4)$ & $38^{\mathrm{b}}$ & $49^{\mathrm{ab}}(4)$ & $71^{\mathrm{a}}(4)$ & 5 \\
\hline
\end{tabular}

* Data represent means of $n$ pigs. Data not sharing a letter are significantly different within experiment $(p<0.05)$.

$\dagger \mathrm{ND}=$ not detectable; tryptophan detection limit $\sim 10 \mu \mathrm{mol} / \mathrm{L}$.

comparisons. Comparison of route of isotope infusion on kinetic parameters (i.e. experiments 2 and 3 ) was made using $t$ test (SAS Institute).

\section{RESULTS}

Weight changes. Piglets were active and healthy throughout all experiments. Initial $(1.62 \pm 0.16 \mathrm{~kg})$ and final weights $(2.84$ $\pm 0.27 \mathrm{~kg}$ ) of all piglets were not different between experiments or among dietary treatment groups within each experiment. Average daily gains were also similar between $\mathrm{IG}_{\text {fed }} /$ $\mathrm{IV}_{\text {dose }}(0.17 \pm 0.03 \mathrm{~kg}), \mathrm{IV}_{\text {fed }} / \mathrm{IV}_{\text {dose }}(0.16 \pm 0.04 \mathrm{~kg})$, and $\mathrm{IG}_{\text {fed }} / \mathrm{IG}_{\text {dose }}(0.18 \pm 0.03 \mathrm{~kg})$ piglets. Gender, day of oxidation, initial weight, final weight, and average daily gain did not significantly affect phenylalanine oxidation. Plateaus in breath ${ }^{14} \mathrm{CO}_{2}$ production and plasma phenylalanine SRA were achieved within $2 \mathrm{~h}$ after initiation of infusions in all pigs in all experiments; furthermore, $\mathrm{CV}$ for individual piglets were $<10 \%$ for each plateau determined.

Experiment 1: parenterally fed/IV dose. Plasma concentrations of several amino acids (tyrosine, glutamate, taurine, glutamine, and citrulline) decreased as the supply of tryptophan (i.e. the limiting amino acid) increased from 0.025 to $0.10 \mathrm{~g} / \mathrm{kg} / \mathrm{d}$ (data not shown); concentrations of these amino acids were similar when tryptophan intake was $>0.10 \mathrm{~g} / \mathrm{kg} / \mathrm{d}$. Plasma tryptophan concentrations were below detection for dietary tryptophan intakes of $0.025-0.10 \mathrm{~g} / \mathrm{kg} / \mathrm{d}$; above these intakes, plasma tryptophan concentrations were positively correlated to tryptophan intake $(p<0.05$, Table 1). Phenylalanine oxidation, expressed as $\mathrm{V}^{14} \mathrm{CO}_{2}$ (not shown), as an absolute amount (Fig. 2) or as a percentage of dose oxidized (Fig. 2) was significantly affected by tryptophan intake $(p<0.05)$. As tryptophan treatment levels increased from 0.025 to $0.10 \mathrm{~g} / \mathrm{kg} / \mathrm{d}$, phenylalanine oxidation significantly decreased $(p<0.05)$. Further increases in dietary tryptophan had no significant effect on phenylalanine oxidation. The break points, or estimates of the mean tryptophan requirement, are shown in Table 2 along with the SEE, upper 95\% CI (i.e. safe intake), and the dual regression coefficient; all dual regressions were significant $(p<0.05)$. Break point data were estimated for $\mathrm{V}^{14} \mathrm{CO}_{2}$, absolute phenylalanine oxidation rate, and percentage of dose oxidized.

Experiment 2: enterally fed/IV dose. With parenteral feeding, plasma concentrations of phenylalanine, tyrosine, valine, alanine, taurine, and glutamine decreased as tryptophan intake increased (data not shown) from 0.025 to $0.10 \mathrm{~g} / \mathrm{kg} / \mathrm{d}$ and remained constant at higher intakes. As in parenterally fed pigs, plasma tryptophan concentrations were below detection for tryptophan intakes from 0.025 to $0.10 \mathrm{~g} / \mathrm{kg} / \mathrm{d}$ and then significantly increased over tryptophan intakes from 0.15 to

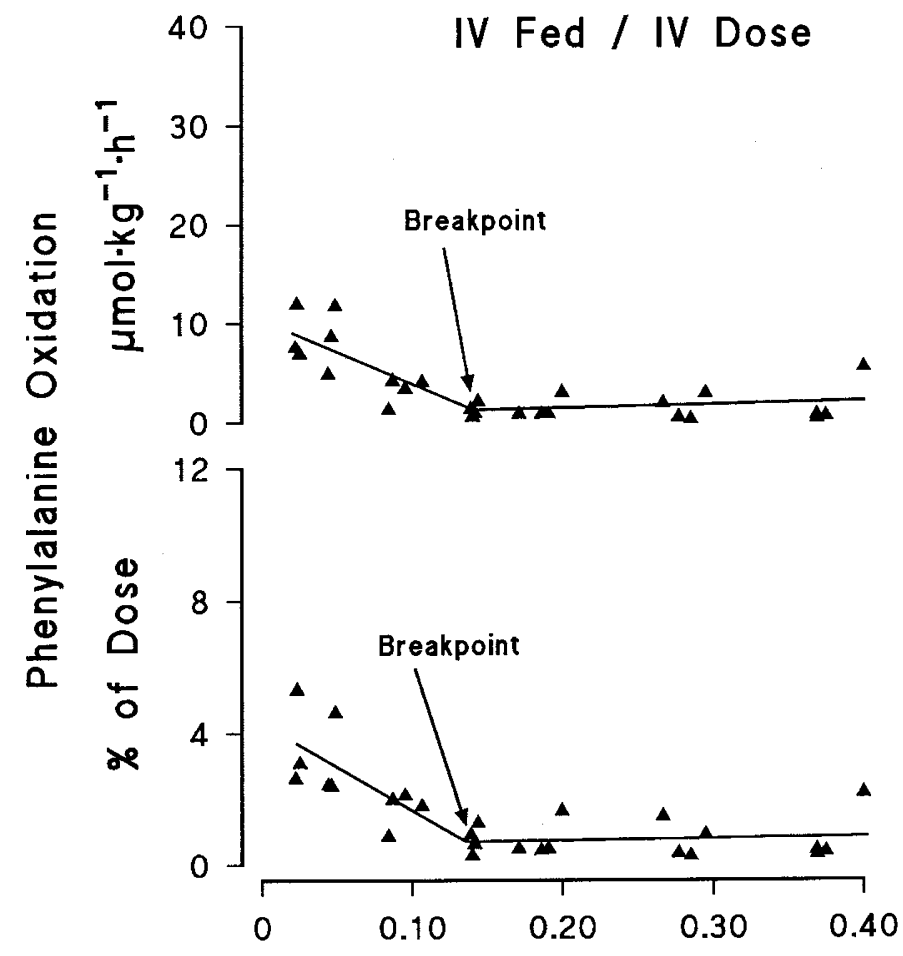

\section{Tryptophan Intake $\left(\mathrm{g} \mathrm{kg}^{-1} \cdot \mathrm{d}^{-1}\right)$}

Figure 2. $\mathrm{L}-\left[1-{ }^{14} \mathrm{C}\right]$ phenylalanine oxidation as absolute rate (top graph) and as percentage dose (bottom graph) in parenterally fed piglets during constant IV isotope infusion. Individual piglets received different dietary levels of tryptophan (which was adjusted for actual dietary intake during the oxidation period) and ${ }^{14} \mathrm{CO}_{2}$ in breath was collected. Break point requirement determined by two-phase linear regression.

$0.40 \mathrm{~g} / \mathrm{kg} / \mathrm{d}(p<0.05$, Table 1). Plasma tryptophan concentrations were not different between parenterally and enterally fed piglets at any tryptophan intake levels $(p>0.05$, Table 1$)$. Phenylalanine oxidation, expressed as $\mathrm{V}^{14} \mathrm{CO}_{2}$ (not shown), as an absolute amount (Fig. 3) or as a percentage of dose oxidized (Fig. 3) was significantly affected by tryptophan intake $(p<$ $0.05)$. All two-phase linear regressions were significant $(p<$ 0.05 ) for $\mathrm{V}^{14} \mathrm{CO}_{2}$, absolute phenylalanine oxidation rate and percentage of dose oxidized, and the break point data are summarized in Table 2.

Experiment 3: enterally fed/IG dose. Plasma concentrations of phenylalanine, tyrosine, taurine, glutamine, and asparagine decreased as tryptophan intake increased (data not shown) from 0.025 to $0.10 \mathrm{~g} / \mathrm{kg} / \mathrm{d}$; these concentrations remained constant at higher intakes. As in the other experiments, plasma tryptophan concentrations were below detection for tryptophan 
Table 2. Evaluation of break point estimates using two-phase linear regression

\begin{tabular}{|c|c|c|c|c|c|}
\hline & $\begin{array}{c}\text { Break point } \\
(\mathrm{g} / \mathrm{kg} / \mathrm{d})\end{array}$ & $\begin{array}{c}\mathrm{SEE}^{*} \\
(\mathrm{~g} / \mathrm{kg} / \mathrm{d})\end{array}$ & $\begin{array}{l}\text { Safe intake } \dagger \\
(\mathrm{g} / \mathrm{kg} / \mathrm{d})\end{array}$ & No. & $r^{2}$ \\
\hline \multicolumn{6}{|l|}{$\mathrm{IV}_{\text {fed }} / \mathrm{IV}_{\text {dose }}$} \\
\hline $\mathrm{V}^{14} \mathrm{CO}_{2}$ & 0.142 & 0.024 & 0.183 & 26 & 0.67 \\
\hline$\%$ Dose oxidized & 0.145 & 0.023 & 0.185 & 26 & 0.68 \\
\hline \multicolumn{6}{|l|}{$\mathrm{IG}_{\mathrm{fed}} / \mathrm{IV}_{\text {dose }}$} \\
\hline $\mathrm{V}^{14} \mathrm{CO}_{2}$ & 0.125 & 0.016 & 0.152 & 31 & 0.68 \\
\hline \multicolumn{6}{|l|}{$\mathrm{IG}_{\mathrm{fed}} / \mathrm{IG}_{\text {dose }}$} \\
\hline $\mathrm{V}^{14} \mathrm{CO}_{2}$ & 0.111 & 0.025 & 0.154 & 31 & 0.53 \\
\hline Oxidation rate & 0.117 & 0.027 & 0.163 & 31 & 0.57 \\
\hline$\%$ Dose oxidized & 0.113 & 0.024 & 0.154 & 31 & 0.56 \\
\hline
\end{tabular}

* SE of the break point estimate.

$\dagger$ Upper 95\% confidence interval of the break point estimate.

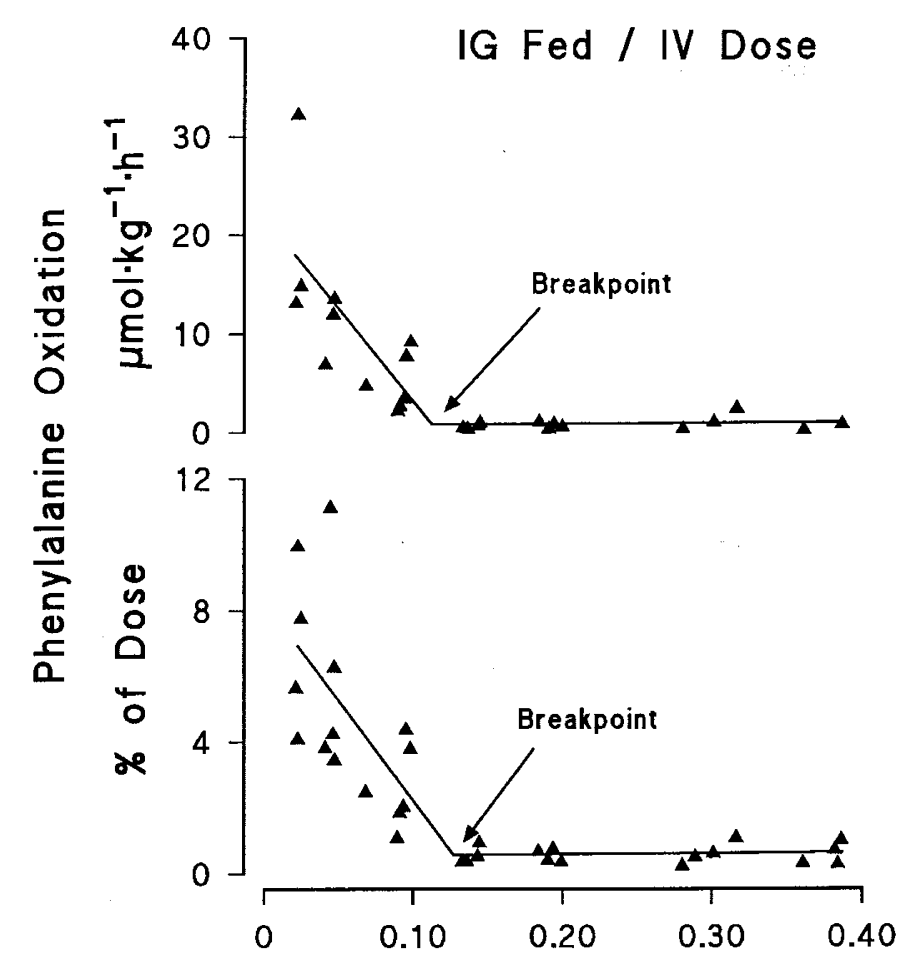

Tryptophan Intake $\left(\mathrm{g} \cdot \mathrm{kg}^{-1} \cdot \mathrm{d}^{-1}\right)$

Figure 3. $\mathrm{L}-\left[1-{ }^{14} \mathrm{C}\right]$ phenylalanine oxidation as absolute rate (top graph) and as percentage dose (bottom graph) in enterally fed piglets during constant IV isotope infusion. Individual piglets received different dietary levels of tryptophan (which was adjusted for actual dietary intake during the oxidation period) and ${ }^{14} \mathrm{CO}_{2}$ in breath was collected. Break point requirement determined by two-phase linear regression.

intakes from 0.025 to $0.10 \mathrm{~g} / \mathrm{kg} / \mathrm{d}$ and increased over tryptophan intakes from 0.15 to $0.40 \mathrm{~g} / \mathrm{kg} / \mathrm{d}(p<0.05$, Table 1$)$. Phenylalanine oxidation, expressed as $\mathrm{V}^{14} \mathrm{CO}_{2}$ (not shown), as an absolute amount (Fig. 4) or as a percentage of dose oxidized (Fig. 4) was also significantly affected by tryptophan intake ( $p$ $<0.05)$. All two-phase linear regressions were significant $(p<$ 0.05 ) for $\mathrm{V}^{14} \mathrm{CO}_{2}$, absolute phenylalanine oxidation rate and percentage of dose oxidized, and the break point data are summarized in Table 2.

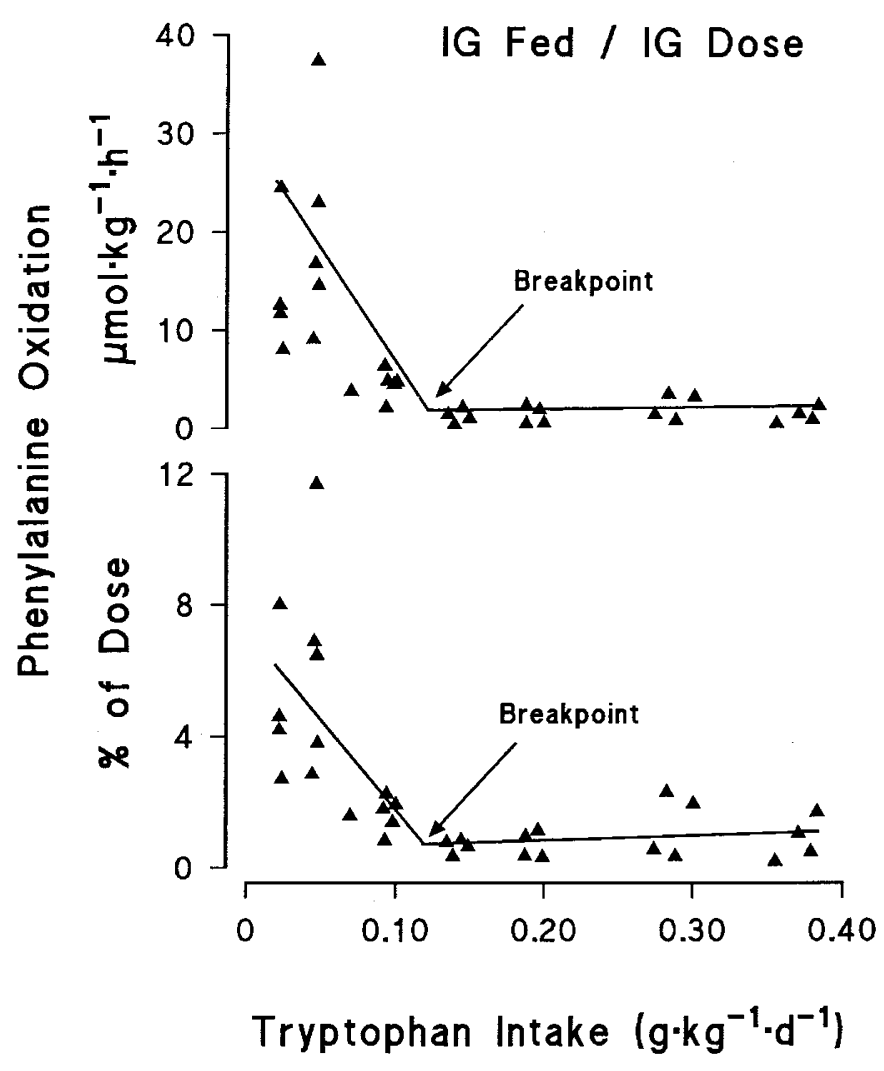

Figure 4. L- $\left[1-{ }^{14} \mathrm{C}\right]$ phenylalanine oxidation as absolute rate (top graph) and as percentage dose (bottom graph) in enterally fed piglets during constant IG isotope infusion. Individual piglets received different dietary levels of tryptophan (which was adjusted for actual dietary intake during the oxidation period) and ${ }^{14} \mathrm{CO}_{2}$ in breath was collected. Break point requirement determined by two-phase linear regression.

To address the effects of route of isotope infusion on phenylalanine kinetics, several parameters were compared in enterally fed pigs from experiments 2 (IV isotope infusion) and 3 (IG isotope infusion); these parameters represent the mean of data from piglets with tryptophan intakes above the break point estimate of requirement (i.e. 0.15 to $0.40 \mathrm{~g} / \mathrm{kg} / \mathrm{d}$ ). Phenylalanine SRA, flux, and oxidation rates are summarized in Table 3, including $\mathrm{V}^{14} \mathrm{CO}_{2}$ and percentage of dose oxidized. 
Table 3. Phenylalanine kinetics in piglets enterally fed adequate tryptophan diets and infused with isotope by $I G$ or IV routes $\%$

\begin{tabular}{lcc}
\hline & IG tracer & IV tracer \\
\hline $\mathrm{V}^{14} \mathrm{CO}_{2}\left(\times 10^{3} \mathrm{dpm} / \mathrm{kg} / \mathrm{h}\right)$ & $58.9 \pm 10.2(16)$ & $36.5 \pm 4.8(16)$ \\
Phenylalanine SRA $\left(\times 10^{3}\right.$ & $39.0 \pm 1.7(16)^{*}$ & $46.9 \pm 2.9(13)$ \\
$\quad$ dpm $/ \mu$ mol $) \ddagger$ & & \\
Phenylalanine flux $(\mu \mathrm{mol} / \mathrm{kg} / \mathrm{h})$ & $199 \pm 14(16)^{*}$ & $146 \pm 12(13)$ \\
Phenylalanine oxidation $(\mu \mathrm{mol} / \mathrm{kg} / \mathrm{h})$ & $1.5 \pm 0.2(16)^{*}$ & $0.9 \pm 0.2(13)$ \\
Percentage dose oxidized & $0.8 \pm 0.2(16)$ & $0.6 \pm 0.1(16)$
\end{tabular}

* Indicates data are significantly different between tracer routes $(p<0.05)$.

$\dagger$ Means \pm SD calculated for $n$ piglets with tryptophan intakes above the break point estimate of requirement (ie $0.15-0.40 \mathrm{~g} / \mathrm{kg} / \mathrm{d}$ ).

$\$$ Plasma-specific radioactivity of phenylalanine at steady state.

\section{DISCUSSION}

Tryptophan metabolism is comprised of a complex pathway that precludes the use of direct oxidation methodology $(21,22)$. The IAAO technique has been demonstrated previously to be an appropriate method of determining amino acid requirements in enterally and parenterally fed piglets $(3,7,23,24)$. Therefore, the IAAO technique was applied to determine both enteral and parenteral tryptophan requirements for neonatal piglets. Previously, we have published estimates for parenteral feeding for phenylalanine (18), tyrosine (25), lysine (7), branched-chain amino acids (23), methionine (24), and threonine (3), including an interpretative review of our findings (2). Recently, we have been able to confirm in human infants our piglet findings about parenteral phenylalanine (18) and tyrosine (25) requirements $(26,27)$, which supports our view that the piglet is a good model in which to estimate the amino acid needs of the human neonate (28).

Phenylalanine oxidation decreased significantly when dietary tryptophan intake was increased from deficient to adequate levels, for both enterally and parenterally fed animals. This negative correlation demonstrated that amino acid oxidation decreased as intake of the limiting amino acid increased, reflecting an increase in protein synthesis until the requirement for tryptophan was met. The tryptophan requirement estimate, or break point, is commonly based on the model that produces the highest regression coefficient and the lowest variance. Using these criteria, absolute phenylalanine oxidation rate appeared to be the most appropriate outcome. However, in each of the present experiments, percentage of dose oxidized was almost as reliable, with model regression coefficients very similar to those for absolute oxidation (Table 2). In previous studies, percentage of dose oxidized provided the most reliable estimates of amino acid requirements, with the lowest error in piglets $(3,7,18,23,24)$ and humans $(22,27,29)$. Using any of the output parameters in Table 2, the break point estimates for enterally fed piglets are well within the CI and SEE for parenterally fed piglets. In addition, the phenylalanine oxidation data were supported by plasma tryptophan concentrations, which were consistently below detection levels in pigs on deficient diets, and increased linearly with tryptophan intakes from 0.15 to $0.40 \mathrm{~g} / \mathrm{kg} / \mathrm{d}$; these data also suggest a break point estimate of requirement between 0.10 and $0.15 \mathrm{~g}$ tryptophan/ $\mathrm{kg} / \mathrm{d}$ (Table 1). We also found a similar correspondence between the indicator break point and plasma concentration break point in studies to determine the tryptophan requirements of adult women (22). Therefore, the enteral and parenteral tryptophan requirements in neonatal piglets appear to be similar. Furthermore, the tryptophan requirements determined in the enterally and parenterally fed animals are similar to those recommended by the National Research Council (30) for 3-5 $\mathrm{kg}$ piglets $(0.15 \mathrm{~g} / \mathrm{kg} / \mathrm{d})$ as well as to those determined by Ball and Bayley for $2.5 \mathrm{~kg}$ piglets $(0.13 \mathrm{~g} / \mathrm{kg} / \mathrm{d})(31)$.

We have previously demonstrated that the route of diet administration substantially influences the requirements of some indispensable amino acids $(3,23,24)$. For example, the parenteral threonine (3) and methionine (24) requirements have been found to be only $45 \%$ and $69 \%$ of the respective mean enteral requirements, probably due to the additional roles of these amino acids in gut mucin and glutathione syntheses. For the branched-chain amino acids, the parenteral requirement was $56 \%$ of the enteral requirement and leucine appeared to be preferentially used by the gut; but the specific metabolic role of leucine in the gut has yet to be elucidated (23). These results regarding the intestinal utilization of these amino acids have been supported by data from Stoll et al. (6) using the portal balance technique; however, they did not measure tryptophan balance. The present study is the first, to our knowledge, to investigate the splanchnic utilization of tryptophan. In contrast to the other amino acids studied, the enteral and parenteral tryptophan requirements in the neonatal piglet are not different, suggesting that the gut is not selectively using tryptophan. This result suggests that the gut's requirement of tryptophan for protein synthesis and/or oxidation does not significantly impact whole-body requirements, possibly due to efficient recycling of tryptophan by an atrophied gut or due to this amino acid's low proportion in protein.

Experiments 2 and 3 were also designed to determine whether changes in phenylalanine kinetics due to route of isotope infusion would change break point estimates of requirement. Phenylalanine kinetics were affected by the route of isotope infusion (Table 3). Although phenylalanine intake was similar among enterally fed piglets, phenylalanine specific activity in plasma (SRA) was significantly higher and flux significantly lower in piglets given IV versus IG tracer $(p<$ 0.05 ) (Fig. 4), similar to previous experiments in adults (1012,32 ). When labeled phenylalanine is given IG, a substantial proportion of the dose is taken up by the gut and liver on first pass, resulting in less label appearing in the central plasma pool. In humans, this splanchnic extraction of label has been estimated at $19-58 \%$ of orally ingested phenylalanine isotope $(10-12)$. In piglets, the proportion of phenylalanine extracted by splanchnic tissues is less variable, with $27 \%$ extraction in the present study and $35 \%$ by Stoll et al. (6). This irreversible extraction changes the rate of isotope appearance in the plasma pool affecting kinetic calculations.

Because of these differences in flux estimates, phenylalanine oxidation rate (i.e. percentage of dose oxidized multiplied by flux) was also significantly higher in IG infused pigs (Table 3). We found that in both enterally fed groups of piglets, those given the phenylalanine tracer IG had $\sim 67 \%$ higher calculated oxidation rate than those receiving IV tracer (Table 3). Because the only difference in treatment between these groups of piglets was that of isotope infusion route, it is clear that the actual 
whole-body phenylalanine oxidation rates did not differ between groups given IG or IV tracers, only the calculated estimates of phenylalanine oxidation were different. It can be argued that kinetic calculations must use an estimate of isotope entry into the sampling pool (i.e. the plasma). However, given the significant effects of splanchnic first-pass metabolism on amino acid kinetics, the inclusion of this splanchnic metabolism (i.e. oral dosing) may actually be a more representative measurement of whole-body kinetics.

Because of this uncertainty in amino acid flux estimates with different routes of isotope infusion, fractional phenylalanine oxidation expressed as percentage of dose is theoretically the most accurate measure. The IAAO technique is designed to measure requirement by monitoring amino acid oxidation over a range of test amino acid intakes. An advantage of this "relative" technique comparing biologic outcomes across dietary intakes is the avoidance of absolute assumptions such as that required for flux. Indeed, it is important to note that, in spite of the problems with parameters that include flux calculations, both measurements (i.e. including or excluding flux) provided similar break point estimates of tryptophan requirements with similar variance. Therefore, although the route of tracer administration alters estimates of phenylalanine SRA and flux, ultimately the tryptophan requirement, as determined by the IAAO technique, remained unaffected. These results confirm similar observations made in adult humans (10). This study has provided further evidence that the IAAO technique is an excellent method for the determination of amino acid requirements, especially in vulnerable populations such as low-birth-weight infants, where oral dosing is the only possible regimen (9).

Low-birth-weight infants require unique nutritional management early in life due to the metabolic immaturity of the gastrointestinal tract and biochemical pathways. The use of the piglet model is a crucial step in determining amino acid requirements for both the parenterally and enterally fed premature infant. Because gastrointestinal development and the profile of amino acid requirements are very similar between piglets and neonates (28), we believe these data are of direct clinical relevance. Indeed, we have recently validated the TPN-fed piglet model in human neonates with respect to parenteral aromatic amino acid requirements (18, 25-27). However, any nutrient requirement comparisons made between growing piglets and infants must account for the much higher growth rate in piglets. Although the requirement for other amino acids, such as threonine (3), methionine (24), and the branched-chain amino acids (23), are substantially greater in enteral versus TPN-fed piglets, this appears not to be true for tryptophan. These results provide further evidence that not all indispensable amino acids are equally used by the gut on first pass. Indeed, the enteral and parenteral requirement for each indispensable amino acid must be empirically determined in the neonatal piglet to develop the optimal amino acid profile for parenteral feeding.

\section{REFERENCES}

1. Pencharz PB 1986 Nutrition of the low birth weight infant. In: Grand RJ, Sutphen JL, Dietz WH (eds) Pediatric Nutrition: Theory and Practice. Butterworths, Boston, pp 313-326
2. Brunton JA, Ball RO, Pencharz PB 2000 Current total parenteral nutrition solutions for the neonate are inadequate. Curr Opin Clin Nutr Metab Care 3:299-304

3. Bertolo RFP, Chen CZL, Law G, Pencharz PB, Ball RO 1998 Threonine requirement of neonatal piglets receiving total parenteral nutrition is considerably lower than that of piglets receiving an identical diet intragastrically. J Nutr 128:1752-1759

4. Bertolo RFP, Chen CZL, Pencharz PB, Ball RO 1999 Intestinal atrophy has a greater impact on nitrogen metabolism than liver by-pass in piglets fed identical diets via gastric, central venous or portal venous routes. J Nutr 129:1045-1052

5. Bertolo RFP, Pencharz PB, Ball RO 2000 Organ and plasma amino acid concentrations are profoundly different in piglets fed identical diets via gastric, central venous or portal venous routes. J Nutr 130:1261-1266

6. Stoll B, Henry J, Reeds PJ, Yu H, Jahoor F, Burrin DG 1998 Catabolism dominates the first-pass intestinal metabolism of dietary essential amino acids in milk-replacerfed piglets. J Nutr 128:606-614

7. House JD, Pencharz PB, Ball RO 1998 The lysine requirement of neonatal piglets receiving total parenteral nutrition determined by the oxidation of the indicator amino acid L- $1{ }^{14} \mathrm{C}$-phenylalanine. Am J Clin Nutr 67:67-73

8. Wykes LJ, Ball RO, Pencharz PB 1993 The development and validation of a total parenteral nutrition model in the neonatal piglet. J Nutr 123:1248-1259

9. Bross R, Ball RO, Pencharz PB 1998 Development of a minimally invasive protocol for the determination of phenylalanine and lysine kinetics in humans during the fed state. J Nutr 128:1913-1919

10. Kriengsinyos W, Wykes LJ, Ball RO, Pencharz PB 2002 Effect of oral and intravenous tracer on the estimate of lysine requirement in healthy adult males using L- $\left[1-{ }^{13} \mathrm{C}\right]$ phenylalanine as an indicator amino acid. J Nutr 132:2251-2257

11. Matthews DE, Marano MA, Campbell RG 1993 Splanchnic bed utilization of leucine and phenylalanine in humans. Am J Physiol 264:E109-E118

12. Biolo G, Tessari P, Inchiostro S, Bruttomesso D, Fongher C, Sabadin L, Fratton MG, Valerio A, Tiengo A 1992 Leucine and phenylalanine kinetics during mixed meal ingestion: a multiple tracer approach. Am J Physiol 262:E455-E463

13. Hoerr RA, Matthews DE, Bier DM, Young VR 1993 Effects of protein restriction and acute refeeding on leucine and lysine kinetics in young men. Am J Physiol 264:E567E575

14. Yu YM, Burke JF, Vogt JA, Chambers L, Young VR 1992 Splanchnic and whole body $\mathrm{L}-\left[1-{ }^{13} \mathrm{C},{ }^{15} \mathrm{~N}\right]$ leucine kinetics in relation to enteral and parenteral amino acid supply. Am J Physiol 262:E687-E694

15. Yu YM, Wagner DA, Tredget EE, Walaszewski JA, Burke JF, Young VR 1990 Quantitative role of splanchnic region in leucine metabolism: $\mathrm{L}-\left[1-{ }^{13} \mathrm{C},{ }^{15} \mathrm{~N}\right]$ leucine and substrate balance studies. Am J Physiol 259:E36-E51

16. el-Khoury AE, Basile A, Beaumier L, Wang SY, Al-Amiri HA, Selvaraj A, Wong S, Atkinson A, Ajami AM, Young VR 1998 Twenty-four-hour intravenous and oral tracer studies with L-[1-13 $\mathrm{C}]$-2-aminoadipic acid and L- $\left[1-{ }^{13} \mathrm{C}\right]$ lysine as tracers at generous nitrogen and lysine intakes in healthy adults. Am J Clin Nutr 68:827-839

17. Hoerr RA, Matthews DE, Bier DM, Young VR 1991 Leucine kinetics from $\left[{ }^{2} \mathrm{H}\right]-$ and $\left[{ }^{13} \mathrm{C}\right]$-leucine infused simultaneously by gut and vein. Am J Physiol 260:E111-E117

18. House JD, Pencharz PB, Ball RO 1997 Phenylalanine requirements determined by using $\mathrm{L}-\left[1-{ }^{14} \mathrm{C}\right]$ phenylalanine in neonatal piglets receiving total parenteral nutrition supplemented with tyrosine. Am J Clin Nutr 65:984-993

19. Bidlingmeyer BA, Cohen SA, Tarvin TL 1984 Rapid analysis of amino acids using pre-column derivatization. J Chromatogr 336:93-104

20. Kim KI, McMillan I, Bayley HS 1983 Determination of amino acid requirements of young pigs using an indicator amino acid. Br J Nutr 50:369-382

21. Zello GA, Wykes LJ, Ball RO, Pencharz PB 1995 Recent advances in methods of assessing amino acid requirements for adult humans. J Nutr 125:2907-2915

22. Lazaris-Brunner G, Rafii M, Ball RO, Pencharz PB 1998 Tryptophan requirement in young adult women determined by indicator amino acid oxidation with L- $\left[{ }^{13} \mathrm{C}\right]-$ phenylalanine. Am J Clin Nutr 68:303-310

23. Elango R, Pencharz PB, Ball RO 2002 The branched-chain amino acid requirement of parenterally fed neonatal piglets is less than the enteral requirement. J Nutr 132:3123-3129

24. Shoveller AK, Brunton JA, Pencharz PB, Ball RO 2003 The methionine requirement is lower in the parenterally fed neonatal piglet than in the enterally fed. J Nutr 133:1390-1397

25. House JD, Pencharz PB, Ball RO 1997 Tyrosine kinetics and requirements during total parenteral nutrition in the neonatal piglet: the effect of glycyl-L tyrosine supplementation. Pediatr Res 41:575-583

26. Roberts SA, Ball RO, Filler R, Moore A, Pencharz PB 1998 Phenylalanine and tyrosine metabolism in neonates receiving parenteral nutrition differing in pattern of amino acids. Pediatr Res 44:907-914

27. Roberts SA, Ball RO, Moore AM, Filler RM, Pencharz PB 2001 The effect of graded intake of glycyl-L-tyrosine on phenylalanine and tyrosine metabolism in parenterallyfed neonates with an estimation of tyrosine requirement. Pediatr Res 49:111-119

28. Ball RO, House JD, Wykes LJ, Pencharz PB 1996 A piglet model for neonatal amino acid metabolism during total parenteral nutrition. In: Tumbleson ME, Schook, LB (eds) Advances in Swine in Biomedical Research. Plenum Press, New York, pp 713-731

29. Bross R, Ball RO, Clarke JT, Pencharz PB 2000 Tyrosine requirements in children with classical PKU determined by indicator amino acid oxidation. Am J Physiol 278:E195-E201

30. National Research Council 1998 Nutrient Requirements of Swine, 10th Ed. National Academy Press, Washington, DC, pp 159-162

31. Ball RO, Bayley HS 1984 Tryptophan requirement of the $2.5-\mathrm{kg}$ piglet determined by the oxidation of an indicator amino acid. J Nutr 114:1741-1746

32. Sanchez M, el-Khoury AE, Castillo L, Chapman TE, Young VR 1995 Phenylalanine and tyrosine kinetics in young men throughout a continuous 24-h period, at a low phenylalanine intake. Am J Clin Nutr 61:555-570 